\title{
DISCIPLINA E TEORIA \\ UMA REFLEXÃO SOBRE A FORMAÇÃO PARTINDO DA FILOSOFIA KANTIANA*
}

\author{
Pedro Casalotti Farhat**** \\ Universidade Federal do ABC (UFABC) - São Bernardo do Campo - SP
}

\begin{abstract}
RESUMO
A intenção deste texto é articular dois temas pouco trabalhados juntos nas interpretações de Kant, embora sejam, segundo nosso entendimento, de fundamental importância para uma plena compreensão da filosofia kantiana e do conhecimento filosófico em geral: a disciplina da razão pura e a filosofia teórica. Pretendemos nos utilizar de algumas outras noções, no entanto, para responder a seguinte pergunta: é possível a formação sem a disciplina filosófica? Isto é, seria possível uma formação teórica (principalmente do conhecimento, mas também do indivíduo) sem uma disciplina ou uma "contribuição negativa" proveniente da filosofia? 0 conceito de formação está, segundo gostaríamos de defender, de um ponto de vista teórico, associado intrinsecamente à disciplina da razão. Assim, indicando como esta é, em geral, relacionada, nas interpretações de Kant, apenas com a pedagogia e com a filosofia prática, gostaríamos de, indo no sentido contrário, tratar do lugar da disciplina da razão em relação ao conceito de formação em seu sentido teórico, isto é, de fundamentação do conhecimento. A disciplina da razão pura revela-se, portanto, uma condição necessária para o filosofar e para a formação do conhecimento em geral.
\end{abstract}

Palavras-chave: disciplina, filosofia teórica, formação.

* Versão corrigida e expandida de trabalho apresentado na II Semana de Filosofia da Metodista, São Bernardo do Campo, SP, 14-17 outubro de 2019.

** Mestrando em Filosofia pela Universidade Federal do ABC (UFABC).

E-mail: pedro.farhat@aluno.ufabc.edu.br 
Não quero ser entendido como um apólogo de Kant, muito menos como um mal intérprete, mas apenas como cometendo o erro inevitável de, ao interpretar, sair da mera reconstrução argumentativa para, partindo de Kant, pensar alguns problemas reais. No meu caso, pensar o lugar da filosofia no aspecto mais amplo dos conhecimentos e saberes humanos. Na imagem que hoje lhes mostrarei, farei uma intolerável apresentação do que entendo pela relação entre conhecimento teórico, isto é, a ciência, e o aspecto negativo indicado pela disciplina da razão fornecida pela filosofia. Isto enquadra-se na minha compreensão geral da noção de método da filosofia extraída da obra de Kant, mas que adquire uma caracterização peculiar para mim. Por essa razão, se me for permitido desenvolver algumas considerações preliminares sobre o método em filosofia, penso que isso será salutar na discussão a que me proponho.

\section{O MÉTOdo CRítico}

0 método na Crítica da razão pura ${ }^{1}$ apresenta-se enquanto signo de uma dupla expressão negativa sobre o conteúdo da filosofia (especialmente da metafísica): uma restrição histórica e outra que chamaríamos epistemológica. A restrição histórica provém mais da leitura dos textos da tradição filosófica e faz coincidir a história da razão com a história do desenvolvimento dos métodos filosóficos. A restrição epistemológica, mais conhecida, está relacionada ao que se concebe como o essencial da filosofia kantiana, isto é, uma salutar posição metafísica que leva em conta principalmente os conteúdos e métodos das ciências, mais fundamentando-os do que disputando espaço com eles. Essas restrições podem parecer fortes demais em relação ao conteúdo, mas quanto à forma, Kant mantém seu método "sistemático", isto é,

\footnotetext{
1 Após toda citação da Crítica, se seguirá a paginação do original alemão, sendo A para a primeira edição (1781) e B para a segunda edição (1787) seguindo o modelo (KrV: A ou B), em que após as letras A ou B aparece a paginação original. Para os demais textos de Kant, como é de praxe, utilizaremos a referência oficial da edição da Academia de Ciências de Berlim (AA), com uma abreviação do título da obra antes do volume e da página, seguindo o modelo (Prol AA IV: 238).
} 
articulado discursivamente através de conceitos em uma justificação jurídica de sua ligação.

Pressupondo esse cenário, a Doutrina do Método da Crítica ganha maior relevo e mais importância do que geralmente se dá a ela, na medida em que expõe essas compreensões metodológicas de Kant, as quais seriam fundamentais para indicar uma resposta para a pergunta acerca do lugar da filosofia em meio as demais ciências. Isso ocorre somente na medida em que o método será uma das formas centrais para que Kant mostre a diferença entre a matemática e a filosofia, fomas de conhecimento racional, mas que não operam segundo os mesmos métodos. Não quero dizer com isso que somente dentro dos estudos kantianos a metodologia chega a ter um papel essencial, mas que em qualquer filosofia, a questão pelo método é inevitável.

\section{A Disciplina...}

Voltando ao texto de Kant, o primeiro capítulo da Doutrina do Método consiste na "disciplina da razão pura", sobre a qual nos voltaremos hoje. A disciplina da razão pura é um mecanismo de controle da razão, não em detrimento desta, segundo Kant, mas para direcioná-la ao seu caminho correto e assim evitar o erro. Como poderia ser diferente? As pretensões disciplinares, vocês diriam, sempre alegam ser para o melhor, mesmo que isso não seja evidente e muito menos justificado adequadamente. No caso de Kant, a justificação provém de todas as concepções estabelecidas ao longo da Estética e da Lógica Transcendentais da Crítica, mas nesse caso o principal fator seria a legitimidade desta enquanto instância de julgamento racional da razão, isto é, enquanto mecanismo da própria razão para se disciplinar. Assim, com essa concepção em vista, a disciplina não se trata de uma demanda que provém de fontes externas à razão, mas apenas da própria razão. Não se trata da disciplina no sentido corrente, em que um agente externo aplica sobre o aluno ou um preso um código de conduta disciplinar. A discussão aqui é transcendental e não envolve apenas o indivíduo humano. 
A filosofia, em especial a metafísica, como expressão discursiva mais genuína da razão, encontra nela mesma o seu critério de acordo: trata-se de uma face da disciplina da razão pura que delimita ao mesmo tempo em que permite o maior avanço desta "ciência" sobre as demais, enquanto instância de fundamentação e esclarecimento das condições de possibilidade do conhecimento em geral. É no recusar o seu lugar de ciência positiva, na Crítica da razão pura, que a metafísica assume, por conseguinte, seu não-lugar na cadeia das doutrinas que promovem "a cultura [Cultur]", mas sim na "formação [Bildung]". Me refiro à seguinte passagem da Doutrina do Método da Crítica:

Denomina-se disciplina à coerção que limita, e por fim elimina, o impulso constante a descumprir certas regras. Ela se distingue da cultura, que deve apenas proporcionar uma habilidade, sem suprimir uma outra que estivesse dada de antemão. Para a formação de um talento, portanto, que já tem por si mesmo um impulso a expressar-se, a disciplina fornecerá uma contribuição negativa, ao passo que a cultura e a doutrina fornecerão uma positiva. (KrV: B 737-8)

Eu gostaria de defender que Kant, neste trecho, não está apenas se referindo ao indivíduo, mas principalmente à própria razão que se disciplina através da Crítica. Isso se justifica pelo "ambiente" em que ocorre este trecho, mas principalmente por conta da ideia de uma disciplina da razão, como já lhes indiquei. Além disso, nossa afirmação dá uma conotação teórica da disciplina que, por vezes, pode ser esquecida em favorecimento de uma leitura prática ou moral, que individualiza a razão em um ser humano particular e que se legitima por trechos da Pedagogia de Kant. Hoje, assim espero conseguir, indicarei ao menos um elemento antagônico entre estes textos.

Não recuso por completo essa ligação, mas apenas aponto que ela deve ser feita cuidadosamente. Gostaríamos de reafirmar o papel teórico-metodológico da disciplina da razão. Lembremos o seguinte trecho da Pedagogia, apenas para que vocês tenham uma amostra da sutileza e da verdadeira proximidade dos textos, os quais podem, e eventualmente devem, ser lidos alinhados.

Kant nos diz na Pedagogia que a "disciplina transforma a animalidade em humanidade" (Ped AA IX: 441). Seguindo uma exposição 
que vai na direção de conceber a educação (a instrução cultural e a disciplina) como constituída socialmente, Kant indica que o animal, por ter instinto [Instinct], não precisa de um cuidado especial, mas apenas de alimento; seu comportamento está já dado. 0 ser humano, em contrapartida, "tem necessidade de sua própria razão. Não tem instinto, e precisa produzir [machen] por si mesmo o projeto de sua conduta. Entretanto, por ele não ter a capacidade imediata de o realizar, mas vir ao mundo em estado bruto, outros devem fazê-lo por ele" (Ped AA IX: 441). Assim, não é o próprio indivíduo que se educa, mas apenas a "espécie humana", que extrai "de si mesma pouco a pouco, com suas próprias forças, todas as qualidades naturais, que pertencem à humanidade. Uma geração educa a outra" (Ped AA IX: 441).

A proximidade dos textos pode ser assustadora a princípio e contém, certamente, um aspecto atrativo. No entanto, mesmo tendo a disciplina nos dois textos uma função negativa para a formação, eu gostaria de defender aqui que no contexto da primeira Crítica, trata-se de um aspecto teórico-metodológico que têm, assim, o objetivo de formar o conhecimento racional humano, e não apenas o conhecimento do indivíduo. A espécie humana é peculiar pois cultiva um tipo de coisa imaterial, a que recorremos sempre para nos educar e manter nossa espécie como dominadora do mundo e da natureza. Este algo é a cultura, mas também a disciplina, e poderíamos resumir esta noção na ideia de razão. A possibilidade de um elemento comum a todos nós, que nos possibilita a comunicação, mas até mesmo o conhecimento, é essencial, de meu ponto de vista, para o que hoje concebemos como sociedade.

\section{... E A TEORIA}

Essa concepção pode parecer assustadoramente metafísica para vocês, ainda mais considerando que se trata aqui de Kant. No entanto, dado que este é o Kant que interpreto e, portanto, mais eu mesmo que o próprio professor de Königsberg, me posiciono como defensor de possíveis críticas de uma possível, apesar de saudável, metafísica. Ainda para permanecer em Kant, no entanto, gostaria de apenas indicar como, 
na Crítica da faculdade de julgar, publicada quase dez anos depois da primeira edição da Crítica da razão pura, Kant recorre precisamente ao que viemos discutindo para, através da teleologia por ele defendida ali, expor a reunião da filosofia teórica com a prática no fim último da natureza, o ser humano enquanto ser instruído e disciplinado, isto é, cultivado na sociedade e no gosto, mas também livre das amarras dos desejos. Trata-se, neste momento, de uma compreensão do ser humano que o favorece como senhor da natureza, mas também como único ser livre, pois efetivamente capaz de, por meio da liberdade adquirida com a disciplina da razão, determinar suas próprias decisões. Kant nos diz:

A promoção da aptidão de um ser racional para quaisquer fins em geral (em sua liberdade, portanto) é a cultura. [...] Mas nem toda cultura é adequada a este fim último da natureza. A cultura da habilidade é certamente a melhor condição subjetiva da aptidão para promover fins em geral; // mas ela não é suficiente para promover a vontade na determinação e escolha de seus fins, o que, no entanto, é essencial em uma aptidão para fins. A última condição da aptidão, a que se poderia chamar cultura do treinamento (disciplina), é negativa e consiste na libertação da vontade em relação ao despotismo dos desejos, pelo qual nos tornamos, presos a certas coisas da natureza, incapazes de escolher por nós mesmos, deixando transformar-se em correntes os impulsos [Triebe] que a natureza nos deu como meros fios condutores para não negligenciar ou mesmo ferir a animalidade em nós, ao passo que somos livres o suficiente para reforçá-los ou afrouxá-los, na medida em que os fins da razão o exijam. (KdU AA V: 431-2)

Não vou mais enfadar vocês com uma exposição minuciosa de outras noções que Kant levanta aqui. 0 principal que gostaria de indicar é a vinculação entre a liberdade de agir e determinar sua própria ação com a disciplina. Somente neste momento, com a admissão de uma instância decisória como a Crítica (entendida em sentido amplo), é que podemos instaurar uma disciplina adequada ao reconhecimento do ser humano enquanto um ser livre e, em consequência, não apenas responsável, mas capaz de desenvolver suas próprias habilidades.

Neste sentido, para retomar os propósitos iniciais pretendidos, mas que infelizmente não terei tempo de desenvolver muito além do que havia dito, gostaria de indicar o lugar da filosofia e, consequente- 
mente da filósofa e do filósofo, como indivíduos ideais, necessariamente relacionados à filosofia universal como a ideia que eles perpetuam. Kant desenvolve, no seguinte trecho da Dialética Transcendental, algo que transpomos agora para a filosofia:

A virtude, e com ela a sabedoria humana [menschliche Weisheit], em toda a sua pureza, são ideias. Mas o sábio (do estoico) é um ideal, i. e., um ser humano que só existe em pensamento, e que é inteiramente congruente com a ideia da sabedoria [der aber mit der Idee der Weisheit völlig kongruiert]. Assim como a ideia fornece a regra, o ideal serve, nesse caso, como modelo para a determinação completa da cópia; e nós não temos outro padrão de medida para nossas ações senão o comportamento desse ser humano divino em nós, com o qual nos comparamos, nos julgamos e assim nos melhoramos, muito embora não possamos jamais atingi-lo (KrV: B 597, tradução modificada).

A figura do filósofo, como a do sábio, é tratada por Kant como um ideal, que portanto não pode ser atingido efetivamente, funcionando como uma espécie de modelo segundo o qual nós, enquanto praticantes da filosofia, deveríamos nos guiar. Neste sentido, assim como o sábio é congruente à ideia da sabedoria, o filósofo ou filósofa o é com a da filosofia, a qual seria, com isso, aquela ciência de todo conhecimento dos fins humanos essenciais. A pessoa que faz filosofia é vista por Kant como a legisladora "da razão humana" e não uma mera "artista da razão", o que revelaria, segundo ele, certa presunção no "denominar-se filósofo e pretender ter-se igualado ao modelo que reside somente na ideia" (KrV: B 867). Espero que, entretanto, não seja essa a impressão que transparece em minha exposição.

A filosofia, assim, em consonância ao que vimos antes sobre a cultura e a formação, associa-se com nossos conhecimentos como a guia ou conhecimento "mestre", ao qual as demais ciências devem recorrer em seu pretenso conhecer, para uma fundamentação adequada. A razão humana, por conseguinte, é intrinsecamente relacionada ao coletivo de indivíduos que, em sociedade, produzem um algo imaterial que resulta na cultura e na tradição. Sem efetivamente apresentar-se deste modo, entretanto, este algo impõe-se sobre nós, de tal modo que sua verdadeira face é, de certa forma, normativa. 
Kant, é verdade, quer recusar este caráter normativo do ideal e resguardar-lhe uma compreensão heurística e regulativa, mas nos parece imperioso apontar um aspecto que vai muito além das expectativas de Kant (pois não envolve aqui uma dinâmica capaz de ser controlada, mas sim uma descrição do que efetivamente acontece). Em um momento urgente como o nosso, no qual a filosofia perde novamente seu, em verdade, pouco reconhecido lugar no conhecimento, recaindo na posição da "rainha de todas as ciências" (KrV: A VIII) a que Kant alude na primeira introdução da Crítica, parece essencial indicar a necessidade de ver a filosofia como necessária para uma formação efetiva do conhecimento e dos indivíduos que perpetuam o conhecimento e efetivamente o constituem.

Para terminar, gostaria de dizer que, se qualquer instituição, em um lugar marcado pela cultura e pela disciplina, deixa de cultivar a filosofia, no meu entender, ela deixa, é claro, de atuar com o rigor e os requisitos necessários para a verdadeira formação de pessoas, mas, principalmente, deixa de lado a própria base de reprodução de nossa sociedade. E isso não é apenas ruim, mas é um crime contra a humanidade.

\section{BibLIOGRAFiA}

KANT, I.Gesammelte Schriften herausgegeben von der Deutschen Akademie der Wissenschaften, anteriormente Königlichen Preussischen Akademie der Wissenschaften, 29 vols. Berlin: Walter de Gruyter, 1902-.

KANT, I. Crítica da razão pura. Tradução de Fernando Costa Mattos. 4. ed. Petrópolis, RJ: Vozes; Bragança Paulista, SP: Editora Universitária São Francisco, 2015.

KANT, I. Crítica da faculdade de julgar. Tradução de Fernando Costa Mattos. Petrópolis, RJ: Vozes; Bragança Paulista, SP: Editora Universitária São Francisco, 2016.

Revista Páginas de Filosofia, v. 8, n. 1-2, p. 55-62, jan/dez. 2019 